University of Nebraska - Lincoln

DigitalCommons@University of Nebraska - Lincoln

USDA Forest Service / UNL Faculty Publications U.S. Department of Agriculture: Forest Service -National Agroforestry Center

2007

\title{
Giving Voice to Wildlands Visitors: Selecting Indicators to Protect and Sustain Experiences in the Eastern Arctic of Nunavut
}

\author{
Alan Watson \\ Aldo Leopold Wilderness Research Institute \\ Brian Glaspell \\ U.S. Fish \& Wildlife Service \\ Neal Christensen \\ Aldo Leopold Wilderness Research Institute \\ Paul Lachapelle \\ Montana State University \\ Vicki Sahanatien \\ University of Alberta \\ See next page for additional authors
}

Follow this and additional works at: https://digitalcommons.unl.edu/usdafsfacpub

Part of the Forest Sciences Commons

Watson, Alan; Glaspell, Brian; Christensen, Neal; Lachapelle, Paul; Sahanatien, Vicki; and Gertsch, Frances, "Giving Voice to Wildlands Visitors: Selecting Indicators to Protect and Sustain Experiences in the Eastern Arctic of Nunavut" (2007). USDA Forest Service / UNL Faculty Publications. 65.

https://digitalcommons.unl.edu/usdafsfacpub/65

This Article is brought to you for free and open access by the U.S. Department of Agriculture: Forest Service -National Agroforestry Center at DigitalCommons@University of Nebraska - Lincoln. It has been accepted for inclusion in USDA Forest Service / UNL Faculty Publications by an authorized administrator of DigitalCommons@University of Nebraska - Lincoln. 


\section{Authors}

Alan Watson, Brian Glaspell, Neal Christensen, Paul Lachapelle, Vicki Sahanatien, and Frances Gertsch 


\title{
Giving Voice to Wildlands Visitors: Selecting Indicators to Protect and Sustain Experiences in the Eastern Arctic of Nunavut
}

\author{
Alan Watson - Brian Glaspell · Neal Christensen · Paul Lachapelle • \\ Vicki Sahanatien · Frances Gertsch
}

Published online: 20 September 2007

(C) Springer Science+Business Media, LLC 2007

\begin{abstract}
Many public land management agencies are committed to understanding and protecting recreation visitor experiences. Parks Canada is deeply committed to that objective for visitors to Canada's National Parks. This 2004 study, informed by a 2003 qualitative study of visitor experiences and influences on those experiences at $\mathrm{Au}-$ yuittuq National Park in Nunavut, worked to bring 50 potential elements of visitor experiences down to five articulated dimensions of the experience that is currently being received at this remote eastern arctic park. A hypothesized set of 17 influences on experiences, also reduced to just two factors with similar response patterns, and with some items that did not flow into the two factors, were used in a regression analysis to understand the relationship between experiences and factors of influence. A sample of $61.8 \%$ (84) of the total recreation visitor
\end{abstract}

A. Watson $(\bowtie) \cdot$ N. Christensen

Aldo Leopold Wilderness Research Institute, USDA Forest Service, Rocky Mountain Research Station, 790 East Beckwith Avenue, Missoula, MT 59801

e-mail: awatson@fs.fed.us

B. Glaspell

Division of Conservation Planning \& Policy, U.S. Fish \&

Wildlife Service, 1011 East Tudor Road, Anchorage, AK 99503

P. Lachapelle

Department of Political Science, Montana State University, P.O.

Box 172240, Bozeman, MT 59717

V. Sahanatien

Parks Canada and the University of Alberta, 7516106 Street

North-West, T6E 4W2 Edmonton, AB, Canada

F. Gertsch

National Human Use Management Specialist, Parks Canada, 25

Eddy Street, K1A OM5 Gatineau, Quebec, Canada population 16 years of age or older was surveyed during deregistration after the trip. Knowledge about the dimensions of the experiences currently received and factors of influence on those experiences can be used to guide selection of indicators for describing objectives and prescribing monitoring protocol.

Keywords Limits of acceptable change - Recreation . Social indicators · Wilderness · Parks management . Visitor experiences $\cdot$ Factors of influence

"The World can tell us everything we want to know. The only problem for the World is that it doesn't have a voice. But the World's indicators are there. They are always talking to us." Quitsak Tarkiasuk (in McDonald and others 1997)

\section{Indicator Development for Monitoring}

For complex systems it is inherently difficult to understand linkages, forces of change, and outcomes. Therefore, both complex social and ecological systems are often studied and influences exerted in a way that focuses on a small number of attributes, or indicators, of those systems that are more confidently understood. These indicators are a key concept in modern policy development and evaluation of both human and nonhuman influences on these systems.

Simple schemes to overcome the intrinsic complexity of most ecological systems have proven inadequate and untrustworthy (Kelly and Harwell 1990). Frønes (2007) suggests that the more complex the indicators, the stronger their power. Many monitoring programs, however, often 
depend upon a small number of indicators and fail to consider the full complexity of the ecological systems they are intended to represent (Dale and Beyeler 2001). Ecological indicators are important to assess condition of the environment, to provide early warnings of changes in the environment, and to diagnose the causes of environmental problems (Dale and Beyeler 2001). For ecological systems, indicators commonly represent key information about structure, function, and composition of the ecological system.

While Cairns and others (1993) strongly suggest that development of a set of indicators to apply to a specific place should vary with different intended uses, they and others have offered broad criteria for indicator selection to represent complex environmental systems. For example, among the seven criteria for indicators advocated by Noss (1990) indicators must be measurable surrogates for environmental end points. While Saltelli (2007) agrees that indicators must be measurable, Dale and Beyeler (2001) go farther to suggest they should be easily measured. Belnap (1998) also suggested good indicators would not only be measurable, but cause little impact on the environment when measured.

Some authors (e.g., Belnap 1998) differentiate between required and desired characteristics of good indicators, but commonly agree that good indicators should be responsive to the context in which they are to be applied. Among many suggested required criteria for environmental indicators include they be sensitive to perturbation (Kelly and Harwell 1990), reliable (Belnap 1998), predict changes that are responsive to management action (Dale and Beyeler 2001), cost effective (Cairns and others 1993), easy to sample (Belnap 1998), and ecologically relevant (Belnap 1998). Noss (1990) suggests that for any monitoring program, particular attention should be paid to specifying the questions that monitoring is intended to answer and validating the relationships between potential indicators and the component of the environment they represent, an important criterion. Costs of indicator measurement are often weighed against established criteria and feasibility to select indicators. Also, choice of indicators is often confounded by vague long-term management goals and objectives (Dale and Beyeler 2001).

Similar to the environmental sciences, social indicators provide a means to track trends along selected social dimensions (Frønes 2007) or evaluate effectiveness of social programs (e.g., Ramirez and others 2006). Social scientists are working to monitor influences on such complex concepts as quality of life (e.g., Baker and Palmer 2006, Iwasaki 2007), reconciliation and truth (e.g., Gibson 2007), health services (e.g., Dolan and White 2006, Marks and others 2007, Ramirez and others 2006), sustainable development (e.g., Rosenström and Kyllönen 2007), and happiness (e.g., Zidanšek 2007). Frønes (2007) describes social indicators as at the center of our modern vocabulary, in fact, a key concept in modern models of climate change, understanding our ability to meet demands for health services, provide educational systems to meet growing needs, and meet expectations for social justice.

Although a concept as important to society as quality of life has been studied with great interest, according to Baker and Palmer (2006), there has been very little success in understanding the factors that have been identified as being predictors of an individual's quality of life. Social scientists similarly struggle with indicators used to monitor health services, with considerable debate about whether policy should be informed by research based on the preferences of healthy members of the general public imagining themselves in different health states or on the reported experiences of patients in those states (Menzel and others 2003). With so many possible indicators to choose from (Ramirez and others (2006) identified 230 potential indicators), such varied applications of social indicators, sometimes focusing on outcomes and sometimes influences on outcomes, and mixed success with adequately representing such complex sociological phenomena with a reduced set of indicators, it is not surprising that, similar to the ecologists, social scientists have provided multiple sets of criteria to guide indicator selection.

Marks and others (2007) concluded that a great many social indicators proposed for use or development are generally not the product of a systematic selection process. Dolan and White (2006) believe that too often the question of which indicators to use for policy purposes is restricted to practical considerations such as costs of data collection. These social scientists caution that different indicators do produce different results. As Smyth and others (2007) suggest, selection of indicators should be based on clear criteria, with specific purposes in mind and careful consideration of the trade-offs between desirable indicator characteristics. Feasibility of social indicators can be influenced by the inclusion of a wide range of stakeholders in the selection process (Rosenström and Kyllönen 2007).

In public lands management, a relatively new area for application of social indicators, one definition of an indicator is a specific parameter that can be monitored to determine whether management objectives are being met. Management objectives are often initially stated in quite general terms, and general categories of concern about influences on these objectives have been termed factors by Stankey and others (1985). One or more indicators are often selected for each of these factors. McCool and Cole (1997), in describing a generic LAC process (the Limits of Acceptable Change), a popular model for making decisions about management options to deal with recreation carrying capacity issues in wilderness, emphasize that when 
indicators are selected, they must be measurable and useful for judging the acceptability of future conditions.

Previous literature on wildland recreation (e.g., Stankey and others 1985, Merigliano 1990) has identified a list of eight desirable characteristics of indicators for public lands management. These characteristics are (1) measurable, (2) reliable, (3) cost-effective, (4) significant, (5) relevant, (6) sensitive, (7) efficient, and (8) responsive.

Measurable indicators have specific measurement protocol. Watson and others (1998) concluded that some managers may be describing indicators in such a general way that there are multiple possibilities for measurement. In this case, each measurement method is actually producing feedback on a slightly different indicator.

Different people should be able to produce similar levels of precision and accuracy of an indicator if it is defined and measured in a reliable fashion.

Indicators should be capable of being measured costeffectively, generally by field personnel using simple equipment and techniques, although selecting an indicator only on the basis of cost-effectiveness can easily lead to poor indicators.

Indicators must relate to significant conditions or features of the wilderness. A good indicator should be capable of detecting changes that, if they occur, would be considered serious problems.

To be relevant to management of recreation resources, the types of changes that are to be detected through the monitoring of indicators should be confined to changes that result from human activities.

Sensitive indicators focus on components that provide an early warning system, alerting managers to deteriorating conditions while there is time to take corrective actions. Indicators are most efficient if they reflect the condition of more than themselves. This can serve to reduce the number of parameters that must be monitored.

Indicators are responsive if the types and or causes of change that are detected are responsive to management intervention.

When Watson and Cole (1992) evaluated selected indicators across several management units, they concluded that three major types of problems were evident. These problems were (1) difficulty in defining indicators in specific and quantitative terms, (2) difficulty in selecting among known indicators because of lack of understanding about which indicators are most significant, and (3) difficulty in selecting indicators due to the lack of reliable monitoring methods.

Stankey and others (1985) suggested selection of indicators that singly, or in combination, best reflect the quality of wilderness condition or wilderness experiences. Lucas and others (1985) suggested selecting "a few" important indicators to represent the many dimensions of resource and social conditions in wilderness. Moore and Polley (2007) advocated selection of indicators based only on importance to visitors. As opposed to simply selecting those potential indicators that visitors rated as most influential on their experiences in three wilderness in the Southern U.S.A., Roggenbuck and others (1993) addressed the efficiency criteria by employing a factor analysis routine that separated potential indicators into unique sets based upon similar patterns of evaluation by visitors. Then, these scientists sequentially applied other criteria to select potential indicators to represent each of these unique dimensions of the experience: measurable, significant, relevant, and responsive.

In reality, it is known that often managers simply adopt indicators that have been selected for application in other planning efforts (Watson and Roggenbuck 1998). There is usually an assumption of significance and no consideration of efficiency. If someone else adopted it, it must be important. Often the lack of significance, efficiency, or relevance of indicators is not apparent until great effort has been invested in inventorying, monitoring, and analyzing information about an indicator.

The purpose of the study reported here was to quantitatively test the relationship between dimensions of the visitor experience and hypothesized factors of influence initially revealed through qualitative interviews of visitors to Auyuittuq National Park in Nunavut. This process is used to develop a list of potential indicators of visitor experiences that can be used for monitoring to protect and sustain them. The emphasis of this kind of research and analysis is primarily based on the need to show indicator efficiency, significance, and relevance.

\section{Indicators for Visitor Experiences}

In wildland recreation management in the U.S.A., and in many other countries, stewardship extends beyond providing a protected land and water resource. A dominant thrust in management for the past 40 years, and thus in research to support management, has been to give managers confidence in managing for visitor experiences. But managers are not commonly well equipped with the tools necessary to set objectives for outcomes associated with visitor experiences. In many situations, managers are looking for direction in establishing visitor experience objectives during the planning process. Among the most common places where managers find this direction are in existing legislation, current agency policy, relevant literature, public input, management decisions at other areas, and research (Watson and others 2004, Watson and Roggenbuck 1998). 
Besides simply the content of published research articles on wilderness visitor experiences, the methods of investigation in this research and the evolution of this research can provide guidance for research on visitor experiences and selecting indicators for monitoring outcomes. For instance, at Juniper Prairie Wilderness in Florida, researchers abandoned previously depended upon quantitative approaches of obtaining visitor input to visitor experience management objectives and employed both qualitative and in situ methodologies to better understand the host of experiences realized by visitors there and the things that were influencing them (Patterson and others 1998, Watson and Roggenbuck 1998, Borrie and Roggenbuck 1998). Management was previously focusing on numbers of intergroup encounters as the primary indicator of wilderness character without having knowledge of efficiency, relevance, or significance of this indicator. The Juniper Prairie research was in great contrast to many previous studies that either focused narrowly on the experiences believed to be prescribed by legislation, those experiences investigated in studies at other places, or upon a single aspect of the experience, like crowding.

Similarly, at Gates of the Arctic National Park and Preserve, Glaspell and others (2003) conducted research to understand the experiences visitors were currently obtaining and identify the factors of influence that either restrict or facilitate receipt of these experiences. This project at Gates of the Arctic was an extensive effort to address the efficiency, significance and relevance criteria for indicators.

The Gates of the Arctic project employed a multi-phase research approach beginning with qualitative visitor interviews followed by a quantitative survey distributed across the visitor population, and concluding with an iterative analysis procedure in which factor analyses, regression modeling, and qualitative insights were used to inform selection of meaningful visitor experience indicators.

Five broadly received experience dimensions and five "factors of influence" were identified in the Gates of the Arctic project. Statistical tests revealed a number of significant relationships between the various factors of influence and experience dimensions, some of which were surprising, in light of previous research. For example, encounters with other visitors have typically been assumed to be a negative influence on wilderness experiences, but at Gates of the Arctic "out-group interaction" was found to be a positive influence for nearly half of visitors. Interpretation of this somewhat counter-intuitive result was greatly facilitated by the qualitative interview phase of the project, which revealed that out-group encounters were often regarded as positive because of the contrast they offered to encounters in other settings.

The multi-phase, multi-method protocol used for the Gates of the Arctic project represented one of the most extensive efforts to date to inform selection of meaningful visitor experience indicators. The project expanded on previous indicator research (e.g., Roggenbuck and others 1993) by grouping "factors of influence" for efficiency and then going a step farther to link these factors with experience dimensions that are specific (and perhaps unique) to Gates of the Arctic, thus establishing significance and relevance as well. Indicators selected according to this method would share these three desirable characteristics.

\section{Auyuittuq National Park, Nunuvat}

This study was conducted to provide information to Parks Canada about the characteristics and quality of recreational experiences in Auyuittuq National Park (ANP) in Nunavut, Canada. Recently, Parks Canada's Nunavut Field Unit identified a need to develop a more complete understanding of the experiences of recreation visitors in an effort to protect various values and monitor influences, and follow new national policy to actively manage to provide visitors with deeply memorable experiences when they visit national parks. Study results will be used to improve current park management and to aid in the creation of the park's management plan (McCool and others in press).

Auyuittuq National Park of Canada was established in 1972. Located on southern Baffin Island, Auyuittuq is 19,707 square kilometers in size. The park is accessible year round and visitors participate in a variety of activities in the park, including skiing, dog team trips, hiking, and climbing. The Akshayuk Pass trail is the focus of most visitor activities, especially in the summer season. Along this 95-kilometer trail, emergency shelters are located approximately one-day's hike apart (approximately every 15 kilometers) and emergency caches are located at difficult river crossings. The southern half of the trail is formalized with cairns and a distinct track. The northern half of the trail is less traveled with no formalized trail, although most hikers follow the Owl River. Park visitors are free to camp at any location in the park, although visitors tend to congregate at the emergency shelters.

\section{Data Collection Methods at Auyuittuq National Park}

The study population included recreational visitors 18 years of age or older to Auyuittuq National Park during the summer of 2004. A visitor was defined as a person who enters or uses the park but does not include native Inuk, researchers, employees, or contractors of Parks Canada or employees or contractors of the Government of Canada acting within the scope of his or her employment or contract. This definition is formally provided in the Inuit 
Impact and Benefit Agreement for Auyuittuq National Park. The team of scientists and managers reporting this research are also studying meanings associated with $\mathrm{Au}$ yuittuq National Park by other users, including scientists and native Inuit (Lachapelle and others 2004), but not reported here.

Visitors were contacted at the Pangnirtung Visitor Center, when they exited the park and were engaged in a required "deregistration." Voluntary response was solicited by a Park employee. All data collection was on-site. Sampling began on July 1, 2004 and continued through September 30. Sampling occurred during business hours at the Parks Canada Visitor Center, approximately 0800 to 1900 hours.

The post-trip survey asked about some trip and visitor characteristics, but focused on 50 items hypothesized from the qualitative interviews in 2003 (Lachapelle and others 2004) to describe aspects of the experience of visitors to Auyuittuq National Park, flowing within five hypothesized themes or dimensions of experiences there. Each person was asked to indicate a level of agreement on whether each of 50 possible experience elements were in fact part of the experience they had. Responses were on a scale of 1 (strongly agree) to 5 (strongly disagree) with a "not applicable" response category as well. Seventeen possible influences on experiences were evaluated on a simple scale of 1 = negative influence, 2 = both negative and positive, and 3 = positive influences on overall experiences, with a "no influence" response also possible. For analysis, any influence was considered to indicate the item as a potential factor of influence. Direction of the influence would be determined by the sign of the coefficients in regression analysis.

\section{Results}

A total of 121 visitors are known to have entered with permit and engaged in the deregistration process at Pangnirtung Visitor Center between July 1 and September 30, 2004. Of these, $84(61.8 \%)$ agreed to complete the questionnaire. Visitors were sometimes hasty in the deregistration process due to aircraft schedules and therefore did not have time to complete the questionnaire, and in some cases emergencies and accidents in the park limited the opportunity for some visitors to receive the questionnaires.

\section{Experience Dimensions}

With a sample size of 84 (even though that is over $60 \%$ of the estimated visitor population for that year), there were some limitations to data analysis possibilities. For factor analysis to identify response patterns on the group of potential elements of important experiences, 50 variables were too many for appropriate interpretation of results. After missing values were imputed with regression, the number of variables was reduced based on negative skewness and low mean scores, limiting further analysis to those experience elements that people most agreed they had experienced. Twenty-five remaining variables were then entered into the factor analysis with oblique rotation, with sixteen of those proving to be useful in describing five factors (Table 1).

An equal amount of visitors $(96.3 \%)$ indicated positive agreement with items factoring into two major experience dimensions (labeled as Challenge \& Accomplishment and Connection with Nature). Those experiencing Challenge \& Accomplishment on this trip had positive agreement with such statements as "The trip was physically challenging," "I felt a sense of accomplishment after traveling in the park," and "There is a feeling about this place unlike any other I have experienced." Connection with Nature was created from positive agreement with such statements as "I felt small compared to the landscape," "I felt I was free to experience the park on my own terms," and "During this trip I felt connected to the natural world."

About $90 \%$ of visitors achieved experiences labeled as the Taste of the Arctic and Learning \& Appreciation. Those expressing agreement with a Taste of the Arctic experience being part of their visit, agreed with statements such as "This park provided unique scenery that cannot be experienced elsewhere," "The arctic environment/setting provides experiences found nowhere else," and "I gained a better appreciation of the arctic environment." Learning \& Appreciation was indicated through agreement with statements such as "I learned a lot about arctic environments/ ecosystems," "Observing the scenic beauty was important to me," and "I felt a sense of freedom in the park."

Isolation in Nature, probably the dominant aspect of wilderness experiences most frequently studied historically, and commonly described as a major benefit of wildland protection, was indicated as part of $77.8 \%$ of visitors' experiences. This dimension was constructed through agreement with "I came here to enjoy the quiet and serenity," "It was important that I was far from civilization," and "During this trip, I felt connected to the natural world."

Factors of Influence and Potential Indicators

Factor analysis, with orthogonal rotation, was used to move the list of 17 potential indicators into a smaller number of forces of influence for efficiency purposes. Again, missing 
Table 1 Factor loadings and percentage of visitors with positive scores on experience dimensions at Auyuittuq National Park, Nunavut

\begin{tabular}{|c|c|c|}
\hline Factor and items $\mathrm{a}^{\mathrm{a}}$ & Factor loading & $\begin{array}{l}\text { Percentage of visitors } \\
\text { with positive agreement }\end{array}$ \\
\hline Challenge \& Accomplishment & & 96.3 \\
\hline The trip was physically challenging & 0.723 & \\
\hline I felt a sense of accomplishment after traveling in the park & 0.675 & \\
\hline There is a feeling about this place unlike any other I have experienced & 0.407 & \\
\hline Observing the scenic beauty was important to me & 0.388 & \\
\hline Connection with Nature & & 96.3 \\
\hline I felt small compared to the landscape & 0.637 & \\
\hline I felt I was free to experience the park on my own terms & 0.590 & \\
\hline During this trip I felt connected to the natural world & 0.578 & \\
\hline I gained a better appreciation of the arctic environment & 0.402 & \\
\hline I enjoyed the challenge of crossing streams & 0.389 & \\
\hline Taste of the Arctic & & 90.1 \\
\hline This park provided unique scenery that cannot be experienced elsewhere & 0.974 & \\
\hline The arctic environment/setting provides experiences found nowhere else & 0.705 & \\
\hline There is a feeling about this place unlike any other I have experienced & 0.615 & \\
\hline I gained a better appreciation of the arctic environment & 0.383 & \\
\hline Learning \& Appreciation & & 88.9 \\
\hline I learned a lot about arctic environment/ecosystems & 0.837 & \\
\hline Observing the scenic beauty was important to me & 0.433 & \\
\hline I felt a sense of freedom in the park & 0.387 & \\
\hline Isolation in Nature & & 77.8 \\
\hline I came here to enjoy the quiet and serenity & 0.801 & \\
\hline It was important that I was far from "civilization" & 0.414 & \\
\hline During this trip, I felt connected to the natural world & 0.536 & \\
\hline I felt a sense of freedom in the park & 0.362 & \\
\hline
\end{tabular}

${ }^{a}$ Common factor analysis with generalized least squares extraction and oblique rotation was used to identify experience dimensions

${ }^{\mathrm{b}}$ Items were measured on a metric 5-point scale with values of Strongly Disagree to Strongly Agree

values were imputed with regression procedures, with a two factor solution emerging as the most interpretable form of the response patterns (Table 2).

Encounters with others (a factor) was formed by similar responses for two potential influences: "number of other visitor groups encountered" and "number of other visitors encountered." Other types of encounters (the other factor) was formed by four potential influences: "encountering groups of more than 8 people," "encountering guided commercial groups," "seeing or hearing low flying aircraft" and "seeing or hearing aircraft flying at high elevation following appropriate flying etiquette." All items not falling naturally into one of these two factors were introduced into a regression attempt to predict experience dimensions as individual factors.

No significant predictors were found for the dimensions Isolation in Nature and Learning \& Appreciation (Table 3). However, the influencing factor "encounters with others" and individual items "physical development" and "quality of pre-trip planning information" significantly predicted $(p$ $\leq 0.05)$ the Taste of the Arctic experience dimension of trips there. Connection with Nature was significantly predicted by two individual items: "quality of pre-trip planning information" and "physical developments." Challenge \& Accomplishment was significantly predicted by "encounters with others." Because this regression model was not corrected for the finite population represented by the data, the results reported here are conservative, with the predictors that were identified as significant being the most significant.

\section{Conclusions}

Based on this analysis, managers have the ability to reasonably debate whether Challenge \& Accomplishment is a worthy and justifiable dimension of the experience of visitors to Auyuittuq National Park. With over $96 \%$ of visitors in 2004 indicating this as a positive contributor to a particular visit, it appears that encounters with others is the 
Table 2 Factor loadings on factors of influence on visitor experiences at Auyuittuq National Park, Nunavut

\begin{tabular}{ll}
\hline Factor and items ${ }^{\mathrm{a}, \mathrm{b}}$ & Factor loading \\
\hline Encounters with others & 0.980 \\
\hline Number of other visitor groups encountered & 0.783 \\
Number of other visitors encountered & \\
Other types of encounters & 0.916 \\
Encountering groups of more than 8 people & 0.671 \\
Encountering guided commercial groups & 0.374 \\
Seeing or hearing low flying aircraft & 0.304 \\
Seeing or hearing aircraft flying at high & \\
elevation following appropriate flying etiquette & \\
a Common factor analysis with generalized least squares extraction \\
and orthogonal Varimax rotation was used to identify factors of \\
influence \\
b Items were measured with a metric 3-point scale with values of \\
"Negative" (-1), "Both negative and positive" or "No influence" (0), \\
and "Positive" (1)
\end{tabular}

Table 3 Regression models relating factors of influence to experience dimensions at Auyuittuq National Park, Nunavut

\begin{tabular}{ll}
\hline Experience dimensions \& significant predictors & Significance level \\
\hline Taste of the Arctic & \\
$\begin{array}{l}\text { Encounters with others } \\
\text { Physical developments (e.g., warden facilities, }\end{array}$ & 0.033 \\
$\quad$ emergency facilities/equipment) & \\
Quality of the pre-trip planning information & 0.044 \\
Connection with Nature & \\
Quality of the pre-trip planning information & 0.001 \\
Physical developments (e.g., warden facilities, & 0.018 \\
$\quad$ emergency facilities/equipment) & \\
Challenge and Accomplishment & \\
Encounters with others & 0.036 \\
Isolation in Nature & \\
No significant predictors & \\
Learning \& Appreciation & \\
No significant predictors
\end{tabular}

The significance levels reported in this table are conservative because of the finite population represented by the data

only successfully tested factor of influence to possibly guide selection of an indicator to monitor relevant influences on achievement of this experience there. A manager would decide whether to monitor both "number of other visitor groups" and "number of other visitors encountered" or select the one with the highest loading on this factor (number of other visitor groups encountered) as not only a relevant influencing factor on this experience dimension, but also possibly the best representative of this composite factor of influence, thus increasing efficiency.

If the Connections with Nature experience dimension is worthy of protection and tracking over time $(96.3 \%$ of visitors reported this experience dimension), it appears that the principle identified items that influence this dimension are the "quality of pre-trip planning information" and "physical developments," both significant predictors. Rereading the qualitative interviews with visitors (Lachapelle and others 2004) provides greater insight into how visitors view the value of pre-trip planning information and how it helped them connect with this place, as well as understand how physical developments, such as warden facilities and emergency facilities and equipment, influence their immersion into nature in this park.

The Taste of the Arctic element of experiences here is a very unique dimension, and had the most significant influences identified. With about $90 \%$ of visitors there in 2004 indicating this was part of their experiences, managers could conclude that it is important to monitor the most efficient representative of the factor "encounters with others," and individual elements of influence "physical developments" and "quality of pre-trip planning information" in order to understand trends in influences on this dimension of the experience. Monitoring of these potential indicators and changes in visitor indications of experiencing this dimension of the place could lead to adjustment in management actions over time.

On the other hand, neither Isolation in Nature nor Learning \& Appreciation were found to be significantly predicted by any of the potential factors of influence included in this study. First of all, that tells us that these things are not heavily influenced by the more common indicators related to encountering other people, as might have been expected, particularly Isolation in Nature. A return to the qualitative portion of the research can provide us with greater insight, maybe even understanding of additional hypothesized factors of influence, given that the ones originally tested did not successfully predict variation in this dimension. For example, from the qualitative study, many visitors talked about a desire and a missed opportunity to learn more about local Inuit culture in Pangnirtung. After testing other possibilities for learning options, one might at least hypothesize for future testing through a monitoring program that "length of stay in neighboring communities (such as Pangnirtung)" could be seen as a factor of influence. If some visitors did not have time to complete the survey, but in earlier qualitative interviews several mentioned not knowing there were options of staying longer in local communities (Lachapelle and others 2004), this could be a potential indicator related to this experience dimension or a slight reformulation of the dimension, based upon qualitatively attained knowledge.

Alternatively, some form of direct measure of a dimension may be appropriate. For example, one possible indicator for Isolation in Nature might be a "self-report on how much freedom was experienced" or "frequency of 
feelings of constraints by park rules and regulations." This insight is also provided from the qualitative interviews. While the factors we hypothesized influenced this dimension and the factors tested were not direct influences, in the short term, until greater understanding of the forces behind this dimension are understood, a more direct measurement method may be appropriate. Frønes (2007) reports a recent emphasis on positive indicators (e.g., Moore and Lipman 2005) in the social sciences, a slight departure from indicator-based systems in the past that have focused on monitoring threats to outcomes (e.g., Stankey and others 1985) instead of outcomes themselves (e.g., Cunningham and Beneforti 2005).

In conclusion, Parks Canada is adamant about managing for visitor experiences. This fairly new emphasis, not just on satisfaction, but on providing deep personal experiences for all Canadians, is aimed at protecting, even restoring, relationships between people and Canadian National Parks in a time of rapid social, biophysical, and policy changes. Identifying the experiences, through research, that people are currently receiving is an important step in setting management objectives. Within the context of legislation, policy, a regional system of opportunities available, and public preferences, decisions can be made consciously about priority experiences that need protection. With additional knowledge about which potential factors of influence are actually related to important experience dimensions, guidance on management to protect target experiences is possible and monitoring of factors of influence or direct monitoring of relevant experience outcomes is a reality.

The role of research can be to provide insight into what is currently happening within protected wildlands and how visitors are reacting to what they encounter there, as well as evaluate potential for possible actions to protect these experiences. Legislation sometimes specifies and sometimes is very vague, only offering examples of what experiences are to be protected within the public purpose of protected places. Often there are many other orientations toward these places, including those of subsistence users, distant stakeholders, and scientific interests, as well as recreation visitors to consider in making management prescriptions. To fully understand these various orientations and justify management actions, this knowledge and long-term monitoring is crucial.

Acknowledgments This research was funded and accomplished cooperatively between Parks Canada, the Aldo Leopold Wilderness Research Institute, and The University of Montana.

\section{References}

Baker DA, Palmer RJ (2006) Examining the effects of perceptions of community and recreation participation on quality of life. Social Indicators Research 75:395-418
Belnap J (1998) Choosing indicators of natural resource condition: a case study in Arches National Park, Utah, USA. Environmental Management 22(4):635-642

Borrie WT, Roggenbuck JW (1998) Describing the wilderness experience at Juniper Prairie Wilderness using experience sampling methods. In: Kulhavy DL, Legg MH, (eds) Wilderness \& natural areas in eastern North America: research, management and planning. Nacogdoches, TX: Stephen F. Austin State University, Arthur Temple College of Forestry, Center for Applied Studies: 165-172

Cairns J, McCormick PV, Niederlehner BR (1993). A proposed framework for developing indicators of ecosystem health. Hydrobiologia 263:1-44

Cunningham J, Beneforti M (2005) Investigating indicators for measuring the health and social impact of sport and recreation programs in Australian indigenous communities. International Review for the Sociology of Sport 40(1):89-98

Dale VH, Beyeler SC (2001) Challenges in the development and use of ecological indicators. Ecological Indicators 1:3-10

Dolan P, White M (2006) Dynamic well-being: connecting indicators of what people anticipate with indicators of what they experience. Social Indicators Research 75:303-333

Frønes I (2007) Theorizing indicators: on indicators, signs and trends. Social Indicators Research 83:5-23

Gibson JL (2007) "Truth" and "Reconciliation" as social indicators. Social Indicators Research 81:257-281

Glaspell B, Watson A, Kneeshaw K, Pendergrast D (2003) Selecting indicators and understanding their role in wilderness experience stewardship at Gates of the Arctic National Park and Preserve. George Wright Forum 20(3):59-71

Iwasaki Y (2007) Leisure and quality of life in an international and multicultural context: what are major pathways linking leisure to quality of life? Social Indicators Research 82:233-264

Kelly JR, Harwell MA (1990) Indicators of ecosystem recovery. Environmental Management 14:527-545

Lachapelle P, McCool S, Watson A (2004) Developing an understanding of landscape interactions, experiences and meanings: Auyuittuq and Quttinirpaaq National Parks of Canada, Nunavut. Report on file at the Aldo Leopold Wilderness Research Institute

Lucas RC, Cole DN, Stankey GH (1985) Research update: what we have learned about wilderness management. In: Frome M, (ed) Issues in wilderness management. Boulder, $\mathrm{CO}$ : Westview Press: pp $173-188$

Marks E, Cargo MD, Daniel M (2007) Constructing a health and social indicator framework for indigenous community health research. Social Indicators Research 82:93-110

McCool SF, Lachapelle PR, Gertsch F, Gosselin H, Sahanatien V In press. Managing recreational experiences in Arctic National Parks: a process for identifying indicators. In: Watson A, Dean L, Sproull J, comps. In Press. Science and stewardship to protect and sustain wilderness values: Eighth World Wilderness Congress symposium; 2005 September 30-October 6; Anchorage, AK. Proceedings RMRS-P-000. Fort Collins, CO: U.S. Department of Agriculture, Forest Service, Rocky Mountain Research Station

McCool SF, Cole DN, comps. (1997) Proceedings-Limits of acceptable change and related planning processes: progress and future directions; 1997 May 20-22; Missoula, MT (Lubrecht Experimental Forest). Gen. Tech. Rep. INT-GTR-371. Ogden,UT: U.S. Department of Agriculture, Forest Service, Rocky Mountain Research Station. 84 p. Cole and McCool (1997)

McDonald M, Arragutainaq L, Novalinga Z (1997) Voices from the Bay: Traditional Ecological Knowledge of Inuit and Cree in the Hudson Bay Bioregion. Canadian Arctic Resource Committee, Environmental Committee of Municipality of Sanikiluaq. 98 p 
Menzel P, Dolan P, Richardson J, Olsen JA (2003) The role of adaptation to disability and disease in health state valuation: a preliminary normative analysis. Social Science and Medicine 55:2149-2158

Merigliano LL (1990) "Indicators to Monitor the Wilderness Recreation Experience" In: Managing America's Enduring Wilderness Resource (Lime DW), (ed) Tourism Center, University of Minnesota Extension Service. St. Paul, MN. pp. 156-62

Moore K, Lipman L (eds) (2005) What do children need to flourish? Conceptualizing and measuring indicators of positive development. New York: Search Institute Series

Moore SA, Polley A (2007) Defining indicators and standards for tourism impacts in protected areas: Cape Range National Park, Australia. Environmental Management 39:291-300

Noss RF (1990) Indicators for monitoring biodiversity: a hierarchical approach. Conservation Biology 4:355-364

Patterson M, Watson A, Williams D, Roggenbuck J (1998) An hermeneutic approach to studying the nature of wilderness experiences. Journal of Leisure Research. 30(4):423-452

Ramirez LKB, Hoehner CM, Brownson RC, Cook R, Orleans CT, Hollander M, Barker DC, Bors P, Ewing R, Killingsworth R, Petersmarck K, Schmid T, Wilkinson W (2006) Indicators of activity-friendly communities: an evidence-based consensus process. American Journal of Preventive Medicine 31(6):515-524

Roggenbuck JW, Williams DR, Watson AE (1993) Defining acceptable conditions in wilderness. Journal of Environmental Management 17(2):187-197

Rosenström U, Kyllönen S (2007) Impacts of a participatory approach to developing national level sustainable development indicators in Finland. Journal of Environmental Management 84(2007):282-298
Saltelli A (2007) Composite indicators between analysis and advocacy. Social Indicators Research 81:65-77

Smyth RL, Watzin MC, Manning RE (2007) Defining acceptable levels of ecological indicators: an approach for considering social values. Environmental Management 39:301-315

Stankey GH, Cole DN, Lucas RC, Petersen ME, Frissell SS (1985) The limits of acceptable change (LAC) system for wilderness planning. Gen. Tech. Rep. INT-176. Ogden, UT: USDA For. Serv., Intermountain Forest and Range Exper. Stn. pp. 37

Watson AE, Patterson M, Christensen N, Puttkammer A, Meyer S (2004) Legislative intent, science and special provisions in wilderness. International Journal of Wilderness 10(1):22-26

Watson AE, Cronn R, Christensen NA (1998) Monitoring inter-group encounters in wilderness. Res. Pap. RMRS-RP-14. Fort Collins, CO: U.S. Department of Agriculture, Forest Service, Rocky Mountain Research Station. p. 20

Watson AE, Roggenbuck JW (1998) Selecting human experience indicators for wilderness: different approaches provide different results. In: Kulhavy DL, Legg MH, (eds) Wilderness \& natural areas in eastern North America: research, management and planning. Nacogdoches, TX: Stephen F. Austin State University, Arthur Temple College of Forestry, Center for Applied Studies: 264-269

Watson AE, Cole DN (1992) LAC indicators: an evaluation of progress and list of proposed indicators. In: Merigliano L, (ed) Ideas for Limits of Acceptable Change process, Book II; Selected papers on wilderness management planning efforts and the LAC process. Washington, DC: USDAFS, Recreation, Cultural Resources and Wilderness Management Staff p. 109

Zidanšek A (2007) Sustainable development and happiness in nations. Energy 32:891-897 